\title{
The role of meniscal repair for prevention of early onset of osteoarthritis
}

\author{
Johannes Weber ${ }^{1}$, Matthias Koch ${ }^{1}$, Peter Angele ${ }^{1,2}$ and Johannes Zellner ${ }^{1 *}$
}

\begin{abstract}
Background: The meniscus plays an important role in the integrity of the knee joint. Therefore, meniscus tissue preserving techniques for the therapy of meniscus injuries seem to be reasonable. One of the important questions is whether meniscal repair can prevent the knee joint from early onset of osteoarthritis.

Methods: According to the review of the current literature, the principles of a successful meniscal repair are explained and the functional outcome and its impact on the prevention of osteoarthritis are analyzed in this article.

Results: Current data show a positive impact of a successful meniscus repair on the functional outcome in longterm. By this a protective effect on the development of osteoarthritis via the repair of meniscus lesions to restore the meniscus integrity can be confirmed. However, higher rates of re-operations in context to meniscus suturing have to be considered.

Conclusion: Due to the improved functional outcomes as well as preventive effect on the development of osteoarthritis within the knee joint in long-term, it is of importance to preserve as much meniscus tissue as possible in meniscus therapy. Patients previously have to be informed about the higher revision rate in context to meniscus suturing.
\end{abstract}

Keywords: Meniscus, Meniscus repair, Prevention, Osteoarthritis of the knee, Review

\section{Review}

\section{Introduction}

The meniscus plays a decisive role for the integrity of the knee joint. It includes shock absorption and transmission, but also joint stabilization and proprioception as well as lubrication and nutrition of the articular cartilage (Makris et al., 2011). Intervention on the meniscus, in particular partial meniscectomies, are one of the most frequently performed operative orthopaedic procedures and underline the impact of this subject. Biomechanical studies have shown that a loss of the meniscus integrity leads to a marked change in kinematics and load distribution in the knee joint. The pressure on the surrounding native articular cartilage subsequently increases. Even a resection of $15-34 \%$ of the meniscus tissue additionally enhances the load on the hyaline cartilage up to $350 \%$ (Radin et al., 1984).

\footnotetext{
* Correspondence: johannes.zellner@ukr.de

${ }^{1}$ Department of Trauma Surgery, University Hospital of Regensburg,

Franz-Josef-Strauss-Allee 11, 93053 Regensburg, Germany

Full list of author information is available at the end of the article
}

In accordance to that, gonarthrosis as a resulting effect of meniscectomy has already been first described a long time ago (Fairbank, 1948) and according to current literature partial meniscectomy is also well known to predispose for the development of gonarthrosis (McDermott \& Amis, 2006; Petty \& Lubowitz, 2011).

Following criterias are defined as risk factors for the development of degenerative changes in context to meniscus injuries (according to Mordecai) (Mordecai et al., 2014):

- partial resection of the lateral meniscus

- resection of larger portions of meniscus tissue

- radial tears reducing or canceling the meniscus ring tension (functional meniscectomy)

- pre-existing cartilage lesions

- persisting ligamentary joint instability

- axial deviation (varus-medial, valgus-lateral)

- obesity

- age $>40$ years

- low activity level 
According to the increasing knowledge concerning the biology and function of the meniscus there is a consensus to preserve as much meniscus tissue as possible in the therapy of meniscus injuries. Thus, different techniques for the therapy of meniscus tears have been developed over time.

Today, meniscus suturing can be seen as gold standard for the regenerative treatment of meniscus lesions (Figs. 1 and 2). Whereas initially this procedure was performed as an open procedure, up to suturing have to be differed: all-inside, outside-in, inside-out.

The vascularization and nutritional situation of the injured meniscus area as well as the type of meniscus tear are decisive of the success of a meniscus reconstruction.

While the inner $2 / 3$ of the meniscus ("white-white") is nourished by diffusion from the synovial fluid, the periphery in the so-called red-red zone has a vascular supply. Between the white-white zone and the vascularized portion a red-white transition zone is located.

Especially the outer third and, to a lesser extent, the red-white transition zone show a regenerative potential with good preconditions for a successful meniscus suturing (Arnoczky, 1999).

The question that arises is whether the patient has a benefit in the short or long term course by maintenance of meniscal substance, and whether, especially in contrast to meniscectomy, the reconstruction of the meniscus can prevent the development of an arthrosis.

\section{Success and failure of meniscus suturing is dependent on localization, time after trauma and genesis}

The general advantage of the (partial) meniscectomy is usually described as a short-term significant improvement of the symptoms and fast rehabilitation. However, even the meniscus suturing is described to go along with good clinical results in more than $80 \%$ of the cases in the short-term outcome (Hulet et al., n.d.). In addition to that, analyzing the short term outcome of patients after partial meniscectomy and meniscus suturing Biedert found that both groups had comparable clinical and radiological results in the IKDC score and postoperative MRI (Biedert, 2000). Thus he concluded that the integrity and function of the meniscus is preferably preserved by meniscus suturing. So, especially in the vascularized red-red zone of the meniscus the endogenous regenerative potential has to be used. Further influencing factors such as sex of localization of the meniscus lesion (medial/lateral site) seemed to not affect the outcome after meniscus preserving therapy.

In addition, the meniscus also has a regenerative potential in the more critical transition zone (Fig. 1). For example, Barber-Westin showed in his review that the healing rate of meniscus suturing in the critical redwhite zone was between $71 \%$ and $84 \%$, depending on the study (Barber-Westin \& Noyes, 2014).

An extended time from meniscus injury to therapy does not represent an absolute contraindication against a reconstructive treatment option. Espejo-Reina et al. report a success rate of $83 \%$ after refixation of bucket handle tears aged between 2 and 60 months (Espejo-Reina et al., 2014). Nevertheless, the healing rate of a meniscus suturing increases, the sooner it is performed. Meniscus lesions, which are treated by a reconstructive technique within 12 weeks, showed a better prognosis (Venkatachalam et al., 2001). These results correlate with the plastic deformation and roll-out phenomenon of older meniscal ruptures, which make a reduction and suturing more difficult. Thus, recent meniscus injuries should be treated promptly.

In a local patient population, 233 recent ACL ruptures with concomitant injuries of cartilage or meniscus being treated within one year after injury were analyzed. The concerned patients were divided into the ones being treated within the first 6 months after injury $(86.3 \%$ of

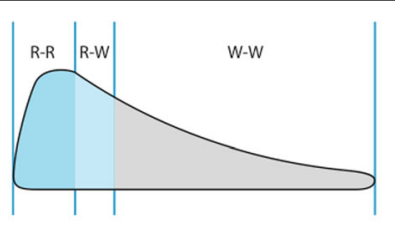

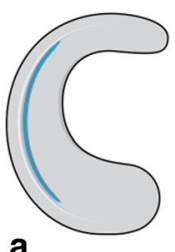

a

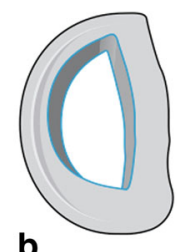

b
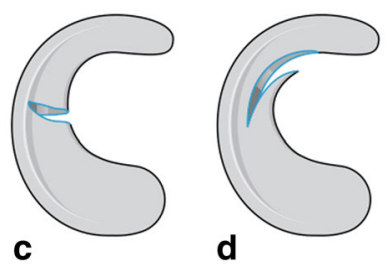

d

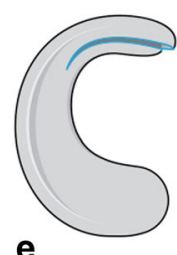

e

Fig. 1 Schematic drawing: Mensical cross section, different tear types and their suturing potential. R-R: red-red-zone, R-W: red-white zone. W-W: white-white-zone: a longitudinal tear, $\mathbf{b}$ bucket handle tear, $\mathbf{c}$ radial tear, $\mathbf{d}$ flap lesion, e flap lesion with meniscal root participation. Different meniscal tear types: especially large bucket handle tears and radial tears that extend to the meniscal rim should be considered to be repaired 


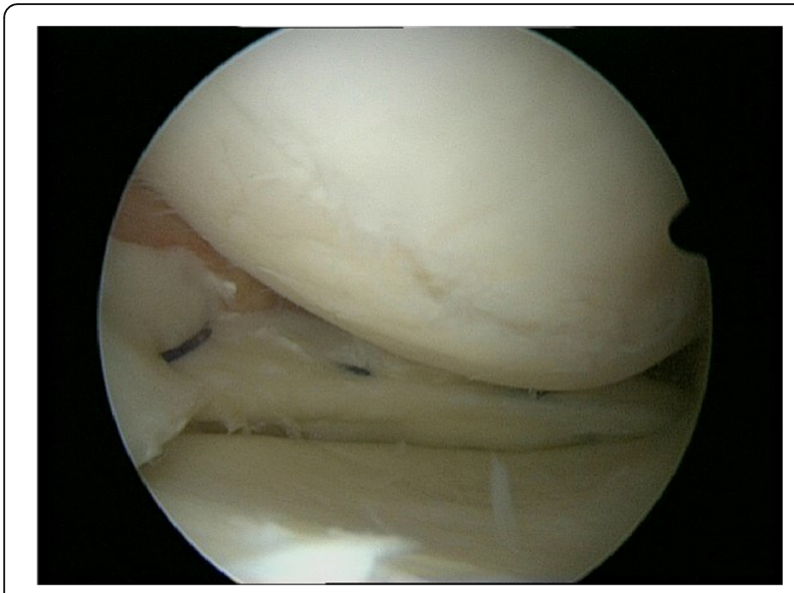

Fig. 2 Meniscus suture. Forty two years old woman, medial meniscus left knee: performed meniscus suture in the red-white area in an early degenerative knee joint. To support endogenous meniscal regeneration by vascular supply a trephination of the meniscus basis was performed prior to the suture. (published in (Zellner \& Angele, 2017))

patients) and the ones being treated between month 7 to $12(13.7 \%)$. The cartilage lesions did not show any differences in treatment at these time points. In contrast, it was found that meniscus injuries associated with ACL reconstruction could be better reconstructed if the surgery was performed in the course of the first 6 months after trauma $(77.2 \%$ reconstructions of medial menisci within the first 6 months as opposed to $46.1 \%$ medial meniscus suturing in the months 7-12 after injury) (Krutsch et al., 2017). These results were confirmed by a further study. Thus meniscus sutures, which were performed within 3 months after trauma, show a higher rate of success $(91 \%)$ than the treatments at a later date (58\% success rate) (Venkatachalam et al., 2001).

Regarding the genesis of the injury, a study showed advantages for traumatically caused injuries unlike degenerative ones in relation to the healing potential (Venkatachalam et al., 2001).

In everyday clinical practice certain algorithms have evolved reflecting this situation. Younger patients with a recent meniscus lesion are more likely to be sutured, whereas older patients with degenerative meniscus lesions, which are an expression of a (starting) general joint wear, receive an arthroscopic partial meniscectomy. In the latter case, however, conservative therapy should also be primarily discussed and considered (Mezhov et al., 2014).

The current literature contains different studies about the failure rate after meniscus suturing. Johnson et al. report a secondary meniscectomy rate of $24 \%$ within 10 years after meniscus reconstruction (Johnson et al., 1999). Also Nepple et al. documented a meniscus suturing failure rate of $23 \%$ regarding an observation period of at least 5 years (Nepple et al., 2012). However, most of these long-term outcome studies/ meta-analysis refer to antique meniscus suturing techniques that were predominantly performed within an open procedure.

Regarding recent arthroscopically meniscus suture techniques, an further improvement of long-term outcomes and reduction of the failure rate is described. Lozano et al. reviewed the outcome after all-inside meniscus suturing and found a mean failure rate of $15 \%$ (Lozano et al., 2007).

Interestingly, the long-term analysis of Nepple et al. showed that the group of failed meniscus sutures were associated with a higher rate of radiological signs of osteoarthritis in the follow-up than the group of patients who had a successful meniscus suturing (Nepple et al., 2012). Based on this fact, it has to be assumed that the intact meniscus tissue has a protective effect on the surrounding cartilage, also regarding a future development of degenerative changes.

To positively influence the success rate of meniscus suturing a precise analysis of the joint status is required. Similar to the preoperative planning in the regenerative therapy of cartilage lesions the evaluation and therapy of additional present joint comorbidities, such as the alignment and joint stability, are a requirement for a successful meniscus reconstruction. Especially unstable joint situations increase the risk for meniscus suturing failures (DeHaven et al., 1995).

\section{How to improve the regenerative potential of the meniscus tissue}

The aim of any meniscus therapy should be to preserve as much meniscus tissue as possible, such as performed by reconstructive techniques like the meniscus suture. The regenerative potential of the meniscus can be further supported by various measures.

So, the refreshing of the margins of meniscus tears is an obligate procedure before each meniscus suture (Fig. 3). Different techniques, such as the trephination of the meniscus margins by awls or K-wires as well as roughening of the defect sites by special meniscus tissue rasps, are available. In a comparative study, Zhang et al. analyzed the effect of such a refreshment of the meniscus defect site by trephination before meniscus suturing (Zhang \& Arnold, 1996). They found a significantly lower failure rate of the meniscus sutures when, in addition to the suture, a trephination was performed before.

In addition to that, a beneficial joint milieu can positively influence the meniscus regeneration. Cannon et al. detected an increased healing rate of $93 \%$ in patients after meniscus suturing and simultaneous ACL replacement in comparison to a healing rate of $50 \%$ in patients, who had an isolated meniscus suture without simultaneous ACL replacement (Cannon Jr \& Vittori, 1992). This 


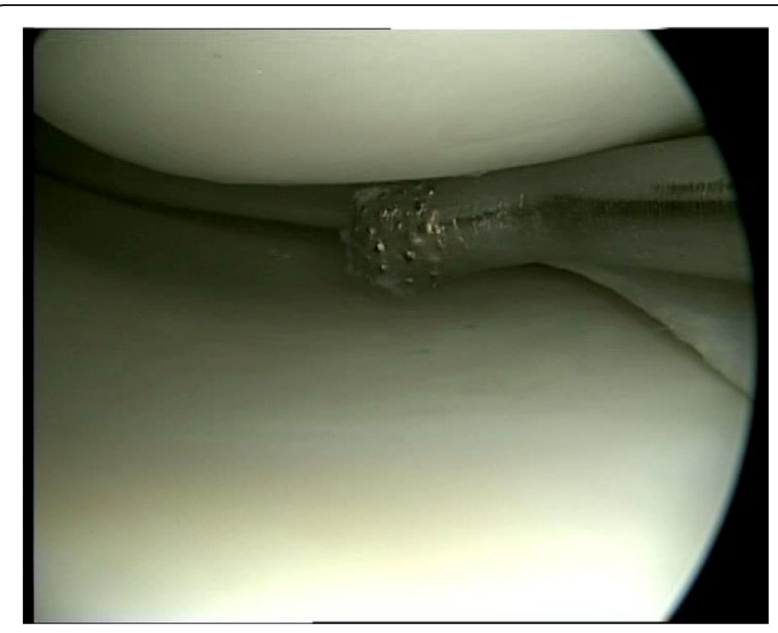

Fig. 3 Preparation of the meniscus lesion. Refreshing of the margins of a meniscus tear by a rasp to induce a slight bleeding as an obligate procedure before meniscus suture to enhance meniscus regeneration (published in (Zellner \& Angele, 2017))

fact has led to a marked increase of the number of meniscus sutures in combination with an ACL replacement in recent years. However, the positive effect presumable bases on the opening of the bone marrow space by drilling the femoral and tibial channels for the ACL replacement. Via these medullary canals mesenchymal stem cells as well as bioactive substances, which support the meniscus regeneration, may influence the joint milieu and arrive to the meniscus defect site. To imitate this effect, some authors also recommend a trephination of the notch before meniscus suturing to support the meniscus healing (Mordecai et al., 2014).

In the future biological augmentation of a meniscus suture, e.g. platelet rich plasma (PRP) or mesenchymal stem cells, could provide an advantage for the regeneration of the bradytrophic meniscus tissue in terms of extension of the indication and reduction of the treatment failure rate of meniscus suturing. Results of own, preclinical studies showed meniscus lesions in the avascular region for example could be healed by the use of mesenchymal stem cells (Zellner et al., 2013; Angele et al., 2008).

Another technique of aumenting mensical tears could be the use of fibrin as material filling the cleft before tightening the futures. The application of fibrin clot repair is intended to serve as a scaffold for repair and to stimulate a reparative process, especially in peripheral lesions (Taylor \& Rodeo, 2013). First few results are promising (Taylor \& Rodeo, 2013; Kamimura \& Kimura, 2014; Jang et al., 2011).

Long-term data of the prevention of osteoarthritis by meniscus reconstruction are also missing for animal models. However the resection of meniscal tissue leads to cartilage lesions and degenerative changes of the knee after a very short time (Zellner et al., 2017).

\section{Treatment failure and complications}

The question which arises when looking at current literature is what exactly has to be considered as a therapy failure. Therefore, a MRI follow up is not always meaningful. Pujol et al. analyzed MRI examinations of the knee joint 10 years after meniscus suturing and found a hyper intense signal in the treated meniscus in $87 \%$ of the cases. The authors concluded that MRI is not suitable for the analysis of the healing status of the meniscus after meniscus suturing (Pujol et al., 2013).

If a treatment failure is defined as a re-operation, there is a clear advantage for the partial meniscectomy. In a review Paxton et al. analyzed 95 studies regarding the outcome and re-operation rate after meniscus therapy (Paxton et al., 2011). For the period of 0 to 4 years after the first meniscus surgery they found a re-operation rate of $1.4 \%$ in the meniscectomy group as opposed to $16.5 \%$ in the meniscus suturing group. In the observation period longer than 10 years, a ratio of $3.9 \%$ for meniscectomy to $20.7 \%$ for meniscus suture was detected. However, the re-operation was defined as a further meniscus therapy. Whether and how many patients in which group had to be converted to for example an arthroplasty procedure remains unclear. Nevertheless, it is assured that the meniscus suture has a higher revision rate over time. This is a fact, which the patient has to be explicitly informed about before meniscus therapy.

On the other hand, the revision surgery has not necessarily to be classified as a complete failure of the meniscus suture. Pujol et al. showed that a partial reconstruction of the meniscus is also possible (Pujol et al., 2011). In 37 patients, the amount of meniscal substance resected during the revision was compared with the initial rupture. They found that in 52\% approximately the same amount, but in $35 \%$ of the cases even less meniscus tissue had to be removed during the revision surgery. Regarding the fact that more meniscus tissue also means enhanced protection for the surrounding cartilage, this could also have a positive effect for the long-term outcome.

\section{Long-term results of meniscus suturing}

The first description of a meniscus suturing technique was published by Annandale in 1885 (Di Matteo et al., 2013). Since then, the treatment options for the reconstructive therapy of meniscus lesions have been significantly advanced, especially by the development of arthroscopically techniques. Regarding studies and meta-analysis describing the long term outcome after meniscus reconstructive therapy, the technical development of the treatment options (open versus arthroscopically procedures) have to be considered. 
Overall, current literature (Table 1) shows a significant positive effect of a meniscus tissue preserving therapy on the knee joint function in long-term. However, the question remains to what extend meniscus preserving techniques, such as meniscus suturing, are able to positively influence the development of degenerative changes within the knee joint.

The integrity of the meniscus is of impact for the prevention of osteoarthritis, such as shown by (partial) meniscectomy. It usually goes along with a loss of symptoms and functional improvement in short-term (Mezhov et al., 2014). However, the long-term outcome after (partial) meniscectomy shows a trend to a degenerative effect. Englund and Lohmander described an association between the degenerative effect and the amount of lost meniscus tissue (Stein et al., 2010). Even if the partial meniscectomy does not show that extended destructive effect, osteoarthritic changes are also documented after a follow up of 16 years after partial meniscectomy (Englund \& Lohmander, 2004). So, Papalia et al. defined the amount of resected meniscus tissue as a predictive factor for the development of osteoarthritis (Englund et al., 2003) (Fig. 4).

In a systematic review concerning the outcome after arthroscopically partial meniscectomy including a minimal follow-up of 8 years and a mean age of 36 years by Petty et al. satisfying results concerning the functional outcome (i.e. Lysholm scoring, Tegner scoring or IKDC scoring) were found (Petty \& Lubowitz, 2011). Nevertheless, all included studies evaluating radiologically based signs of osteoarthritis in the index and contralateral site detected significantly enhanced signs of osteoarthritis in the group having a knee operation. Comparing the medial and lateral meniscus, especially partial meniscectomy of the lateral meniscus shows a negative influence on the development of degenerative changes (Papalia et al., 2011). In this context Lee et al. examining 49 patients after subtotal resection of the lateral meniscus and having lateral meniscus replacement throughout after a mean of 4.5 years. The authors observed a significant development of signs of osteoarthritis according to the

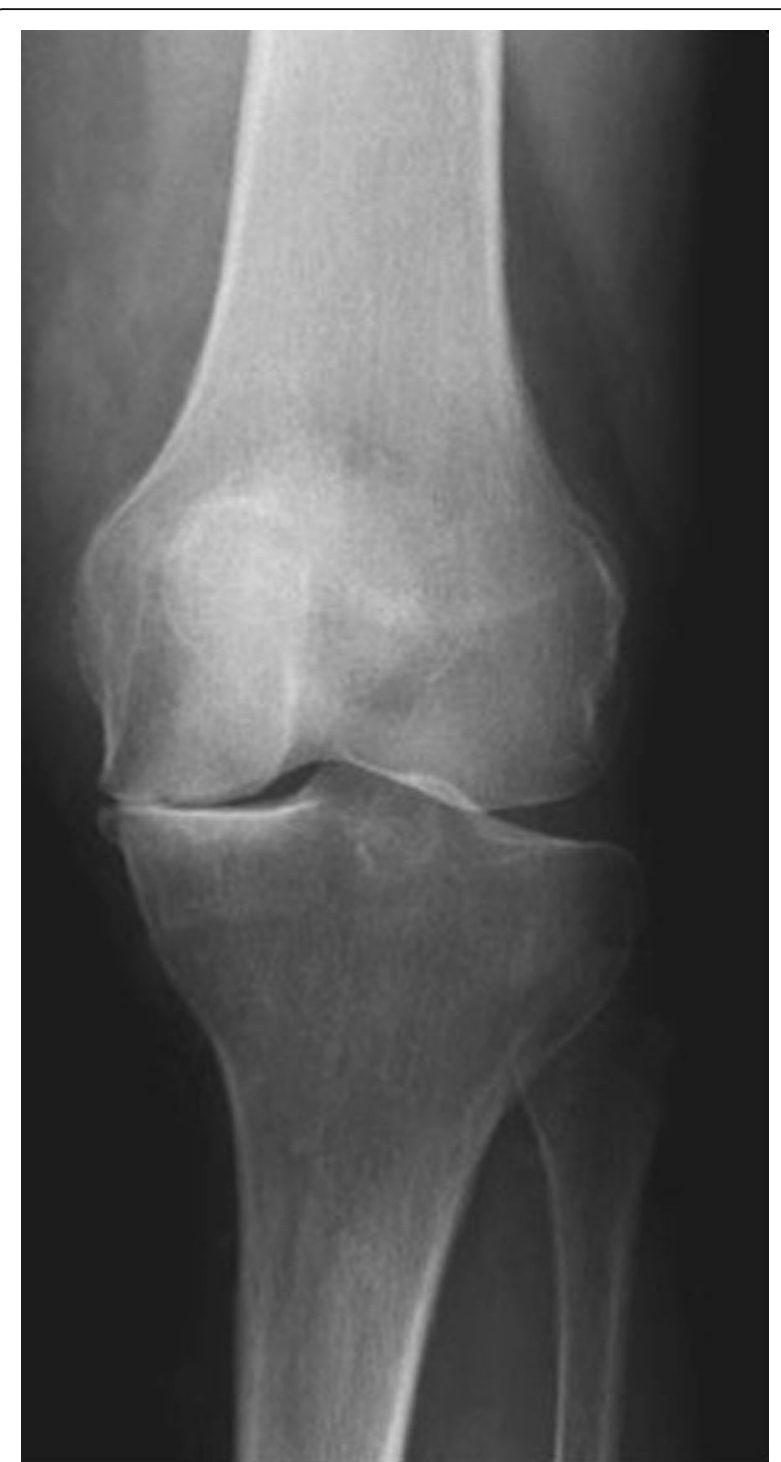

Fig. 4 X-ray post subtotal meniscectomy. Forty two year old man: $X$-ray of a left knee joint 7 years after subtotal meniscectomy. It shows a lost joint line on the medial site and signs of osteoarthritis of the knee (published in (Zellner \& Angele, 2017))

Table 1 Overview of performed studies conferning long-term outcome after meniscus suturing

\begin{tabular}{|c|c|c|c|}
\hline Author & Study design & Follow-up period & Results \\
\hline $\begin{array}{l}\text { Tengrootenhuysen et al. } 2011 \\
\text { (Di Matteo et al., 2013) }\end{array}$ & $\begin{array}{l}\text { Retrospective cohort study, } \\
n=119\end{array}$ & Follow up up to $5 y$ & $\begin{array}{l}\text { Improved IKDC \& Lysholm after } \\
\text { meniscus suturing }\end{array}$ \\
\hline $\begin{array}{l}\text { Xu et al. } 2015 \\
\text { (Tengrootenhuysen et al., 2011) }\end{array}$ & $\begin{array}{l}\text { Meta analysis }(n=367) \text {, } \\
\text { comparison of meniscus suturing } \\
\text { vs. partial meniscectomy }\end{array}$ & Follow up up to 7 y & $\begin{array}{l}\text { Improved IKDC \& Lysholm as } \\
\text { well as reduced loss of function } \\
\text { in suturing group }\end{array}$ \\
\hline $\begin{array}{l}\text { Stein et al. 2010, } \\
\text { (Xu \& Zhao, 2015) }\end{array}$ & $\begin{array}{l}\text { Cohort study }(n=81) \text { : } \\
\text { comparison of meniscus suturing } \\
\text { vs. partial meniscectomy }\end{array}$ & Follow up up to $9 y$ & $\begin{array}{l}\text { Higher return to pre-injury } \\
\text { activity level in suturing group }\end{array}$ \\
\hline (Majewski et al., 2009) & $\begin{array}{l}\text { Retrospective cohort study, } \\
n=84\end{array}$ & Follow up up to $10 \mathrm{y}$ & $\begin{array}{l}\text { rotational stability after successful } \\
\text { suturing as high as in uninjured } \\
\text { knees }\end{array}$ \\
\hline
\end{tabular}


Kellgren-Lawrence classification and a progressive loss of the joint line. Though, the process of progressive joint degeneration could have positively been influenced by meniscus replacement (Salata et al., 2010).

In case of untreated meniscus root tears, Steineman et al. 2017 (Steineman et al., 2017) demonstrated early OA changes in an animal model when leaving anterior meniscal root tears untreated for 8 weeks. Currently, no clinical studies are available which analyse the influence of repairing mensical root tears on progression of osteoathritis.

In contrast to the (partial) meniscectomy meniscus preserving techniques such as meniscus suturing show a cartilage protective effect in long-term. Noyes et al. evaluated the meniscal status of 33 patients having meniscus suture after a mean follow-up of 16.8 years by MRT scan. No degenerative changes in the operated compartment or differences concerning the status of degeneration in comparison to the healthy, contralateral site were found in patients after having successful meniscus suturing (Lee et al., 2016). Further studies described a progress of radiological signs of osteoarthritis after meniscus suturing in long-term, however these results showed just a mild progress of degenerative changes (Nepple et al., 2012). Johnson et al. compared the injured and contralateral knee joint 10 years after meniscus suturing on a radiological base (Johnson et al., 1999). While $8 \%$ of these patients developed osteoarthritic signs on the operated site, degenerative changes were also found in $3 \%$ of the contralateral, intact knee joints. Furthermore Tengrootenhuysen et al. analysed differences between patients after a successful meniscus suture and patients in whom the meniscus suture failed (Di Matteo et al., 2013). In 14\% of the patients having a successful reconstruction of the meniscus signs of osteoarthritis were documented in X-ray. In contrast to that, in more than $80 \%$ of the patients with a failed meniscus preserving therapy signs of an osteoarthritis were seen.

Regarding the development of gonarthrosis, techniques preserving a functional intact meniscus tissue are also of advantage in comparison to partial meniscectomy. Stein et al. showed no progress of radiological signs of osteoarthrosis in $81 \%$ of the evaluated patients after almost 9 years after meniscus suturing, whereas a stop of a degenerative progress was only seen in $40 \%$ of the patients after partial meniscectomy (Xu \& Zhao, 2015). Similar results were found by Paxton et al. (Paxton et al., 2011). While $78 \%$ of the patients had no progress of the osteoarthritic status according to the Xray after having reconstruction of the meniscus, just in $64 \%$ of the patients, who had partial meniscectomy, no further development of gonarthrosis was detected. Especially in younger patients further studies showed also clear advantages of the meniscus preserving techniques in contrast to the partial meniscectomy concerning osteoarthrosis preventing qualities (Noyes et al., 2011).

\section{Conclusion}

Meniscus preserving techniques to obtain a functional intact meniscus after meniscus injury in long-term are of great importance for the prevention of the development of osteoarthritis in the knee joint. Different significances and distributions of the studies are probably based on the heterogeneity of the evaluated patients, the different operation techniques and outcome analyses.

The authors of the manuscript recommend, based on the studies cited above, to try to perform meniscus preserving techniques, such as meniscus suturing, whenever achievable, and if a partial meniscetomy is necessary, to save as much meniscus tissue as possible.

Additionally, with suture treated patients always have to be informed about the failure rate, the extended period of rehabilitation and the higher rate of surgical revisions. However, further research projects, concerning for example augmented meniscus suture techniques, are necessary to reduce the failure rate and extend the indicational criterias for the meniscus preserving techniques.

\section{Abbreviations \\ ACL: Anterior cruciate ligament; IKDC: International knee documentation committee; MRI: Magnetic resonance imaging; PRP: Platelet rich plasma}

\section{Funding}

No funding.

Availability of data and materials

References see PubMed.gov.

Authors' contributions

MK literature review, wrote manuscript. JW literature review, help writing. PA literature review, help writing. JZ literature review, help writing. All authors read and approved the final manuscript.

Ethics approval and consent to participate

Not applicable.

Consent for publication

Not applicable.

Competing interests

The authors declare that they have no competing interests.

\section{Publisher's Note}

Springer Nature remains neutral with regard to jurisdictional claims in published maps and institutional affiliations.

\section{Author details}

'Department of Trauma Surgery, University Hospital of Regensburg, Franz-Josef-Strauss-Allee 11, 93053 Regensburg, Germany. ${ }^{2}$ sporthopaedicum Regensburg/Straubing, Hildegard von Bingen Strasse 1, 93053 Regensburg, Germany. 


\section{Received: 5 October 2017 Accepted: 8 March 2018}

\section{Published online: 02 April 2018}

\section{References}

Angele P, Johnstone B, Kujat R, Zellner J, Nerlich M, Goldberg V, Yoo J (2008) Stem cell based tissue engineering for meniscus repair. J Biomed Mater Res A 85(2):445-455. https://doi.org/10.1002/jbm.a.31480

Arnoczky SP (1999) Building a meniscus. Biologic considerations. Clin Orthop Relat Res (367 Suppl):S244-S253

Barber-Westin SD, Noyes FR (2014) Clinical healing rates of meniscus repairs of tears in the central-third (red-white) zone. Arthroscopy : the journal of arthroscopic \& related surgery : official publication of the Arthroscopy Association of North America and the International Arthroscopy Association 30 (1):134-146. https://doi.org/10.1016/j.arthro.2013.10.003

Biedert RM (2000) Treatment of intrasubstance meniscal lesions: a randomized prospective study of four different methods. Knee Surg Sports Traumatol Arthrosc 8(2):104-108. https://doi.org/10.1007/s001670050195

Cannon WD Jr, Vittori JM (1992) The incidence of healing in arthroscopic meniscal repairs in anterior cruciate ligament-reconstructed knees versus stable knees. Am J Sports Med 20(2):176-181. https://doi.org/10.1177/ 036354659202000214

DeHaven KE, Lohrer WA, Lovelock JE (1995) Long-term results of open meniscal repair. Am J Sports Med 23(5):524-530. https://doi.org/10.1177/ 036354659502300502

Di Matteo B, Tarabella V, Filardo G, Vigano A, Tomba P, Marcacci M (2013) Thomas Annandale: the first meniscus repair. Knee Surg Sports Traumato Arthrosc 21(9):1963-1966. https://doi.org/10.1007/s00167-013-2490-3

Englund M, Lohmander LS (2004) Risk factors for symptomatic knee osteoarthritis fifteen to twenty-two years after meniscectomy. Arthritis Rheum 50(9):2811-2819. https://doi.org/10.1002/art.20489

Englund M, Roos EM, Lohmander LS (2003) Impact of type of meniscal tear on radiographic and symptomatic knee osteoarthritis: a sixteen-year followup of meniscectomy with matched controls. Arthritis Rheum 48(8):2178-2187. https://doi.org/10.1002/art.11088

Espejo-Reina A, Serrano-Fernandez JM, Martin-Castilla B, Estades-Rubio FJ, Briggs KK, Espejo-Baena A (2014) Outcomes after repair of chronic bucket-handle tears of medial meniscus. Arthroscopy : the journal of arthroscopic \& related surgery : official publication of the Arthroscopy Association of North America and the International Arthroscopy Association 30 (4):492-496. https://doi.org/ 10.1016/j.arthro.2013.12.020

Fairbank TJ (1948) Knee joint changes after meniscectomy. J Bone Joint Surg Br 30B(4):664-670

Hulet C, Pereira H, Peretti G, Denti M eds. Surgery of the Meniscus. 1st ed. London: Springer; 2016

Jang SH, Ha JK, Lee DW, Kim JG (2011) Fibrin clot delivery system for meniscal repair. Knee Surg Relat Res 23(3):180-183. https://doi.org/10. 5792/ksrr.2011.23.3.180

Johnson MJ, Lucas GL, Dusek JK, Henning CE (1999) Isolated arthroscopic meniscal repair: a long-term outcome study (more than 10 years). Am J Sports Med 27(1): 44-49. https://doi.org/10.1177/03635465990270011501

Kamimura T, Kimura M (2014) Meniscal Repair of Degenerative Horizontal Cleavage Tears Using Fibrin Clots: Clinical and Arthroscopic Outcomes in 10 Cases. Orthop J Sports Med 10(2(11)):2325967114555678. https://doi.org/10. $1177 / 2325967114555678$

Krutsch W, Zellner J, Baumann F, Pfeifer C, Nerlich M, Angele P (2017) Timing of anterior cruciate ligament reconstruction within the first year after trauma and its influence on treatment of cartilage and meniscus pathology. Knee Surg Sports Traumatol Arthrosc 25(2):418-425. https://doi.org/10.1007/ s00167-015-3830-2

Lee BS, Bin SI, Kim JM (2016) Articular cartilage degenerates after subtotal/Total lateral meniscectomy but radiographic arthrosis progression is reduced after meniscal transplantation. Am J Sports Med 44(1):159-165. https://doi.org/10. $1177 / 0363546515612076$

Lozano J, Ma CB, Cannon WD (2007) All-inside meniscus repair: a systematic review. Clin Orthop Relat Res 455:134-141. https://doi.org/10.1097/BLO. 0b013e31802ff806

Majewski M, Stoll R, Müller W, Friederich NF (2009) Rotatory stability of the knee after arthroscopic mensicus suture repair: a 5-to17-year follow-up study of isolated medial and lateral meniscus tears. Acta Orthopaedica Belgium 75(3):354-359
Makris EA, Hadidi P, Athanasiou KA (2011) The knee meniscus: structurefunction, pathophysiology, current repair techniques, and prospects for regeneration. Biomaterials 32(30):7411-7431. https://doi.org/10.1016/j. biomaterials.2011.06.037

McDermott ID, Amis AA (2006) The consequences of meniscectomy. J Bone Joint Surg Br 88(12):1549-1556. https://doi.org/10.1302/0301-620X.88B12. 18140

Mezhov V, Teichtahl AJ, Strasser R, Wluka AE, Cicuttini FM (2014) Meniscal pathology - the evidence for treatment. Arthritis research \& therapy 16(2):206. https://doi.org/10.1186/ar4515

Mordecai SC, Al-Hadithy N, Ware HE, Gupte CM (2014) Treatment of meniscal tears: an evidence based approach. World journal of orthopedics 5(3):233-241. https://doi.org/10.5312/wjo.v5.i3.233

Nepple JJ, Dunn WR, Wright RW (2012) Meniscal repair outcomes at greater than five years: a systematic literature review and meta-analysis. J Bone Joint Surg Am 94(24):2222-2227. https://doi.org/10.2106/jbjs.k.01584

Noyes FR, Chen RC, Barber-Westin SD, Potter HG (2011) Greater than 10-year results of red-white longitudinal meniscal repairs in patients 20 years of age or younger. Am J Sports Med 39(5):1008-1017. https://doi.org/10.1177/ 0363546510392014

Papalia R, Del Buono A, Osti L, Denaro V, Maffulli N (2011) Meniscectomy as a risk factor for knee osteoarthritis: a systematic review. Br Med Bull 99:89-106. https://doi.org/10.1093/bmb/ldq043

Paxton ES, Stock MV, Brophy RH (2011) Meniscal repair versus partial meniscectomy: a systematic review comparing reoperation rates and clinical outcomes. Arthroscopy : the journal of arthroscopic \& related surgery : official publication of the Arthroscopy Association of North America and the International Arthroscopy Association 27 (9):1275-1288. https://doi.org/10.1016/j.arthro.2011.03.088

Petty CA, Lubowitz JH (2011) Does arthroscopic partial meniscectomy result in knee osteoarthritis? A systematic review with a minimum of 8 years' followup. Arthroscopy : the journal of arthroscopic \& related surgery : official publication of the Arthroscopy Association of North America and the International Arthroscopy Association 27 (3):419-424. https://doi.org/10.1016/ j.arthro.2010.08.016

Pujol N, Barbier O, Boisrenoult P, Beaufils P (2011) Amount of meniscal resection after failed meniscal repair. Am J Sports Med 39(8):1648-1652. https://doi. org/10.1177/0363546511402661

Pujol N, Tardy N, Boisrenoult P, Beaufils P (2013) Magnetic resonance imaging is not suitable for interpretation of meniscal status ten years after arthroscopic repair. Int Orthop 37(12):2371-2376. https://doi.org/10. 1007/s00264-013-2039-6

Radin EL, de Lamotte F, Maquet P (1984) Role of the menisci in the distribution of stress in the knee. Clin Orthop Relat Res (185):290-294

Salata MJ, Gibbs AE, Sekiya JK (2010) A systematic review of clinical outcomes in patients undergoing meniscectomy. Am J Sports Med 38(9):1907-1916. https://doi.org/10.1177/0363546510370196

Stein T, Mehling AP, Welsch F, von Eisenhart-Rothe R, Jager A (2010) Long-term outcome after arthroscopic meniscal repair versus arthroscopic partial meniscectomy for traumatic meniscal tears. Am J Sports Med 38(8):1542-1548. https://doi.org/10.1177/0363546510364052

Steineman BD, LaPrade RF, Santangelo KS, Warner BT, et al. (2017) Early osteoarthritis after untreated anterior meniscal root tears: an in vivo animal study. Orthopaedic journal of sports medicine 27; 5 (4) eCollection 2017 Apr. https://doi.org/10.1177/2325967117702452

Taylor SA, Rodeo S (2013) Augmentation techniques for isolated meniscal tears Curr Rev in Musculoskeletal Med 6(2):95-101

Tengrootenhuysen M, Meermans G, Pittoors K, van Riet R, Victor J (2011) Longterm outcome after meniscal repair. Knee Surg Sports Traumatol Arthrosc 19(2):236-241. https://doi.org/10.1007/s00167-010-1286-y

Venkatachalam S, Godsiff SP, Harding ML (2001) Review of the clinical results of arthroscopic meniscal repair. Knee 8(2):129-133

Xu C, Zhao J (2015) A meta-analysis comparing meniscal repair with meniscectomy in the treatment of meniscal tears: the more meniscus, the better outcome? Knee Surg Sports Traumatol Arthrosc 23(1):164-170. https://doi.org/10.1007/s00167-013-2528-6

Zellner J, Angele P (2017) Rolle des Meniskuserhalts in der Arthroseprotektion. Arthroskopie 30(2):121-127. https://doi.org/10.1007/s00142-017-0134-1

Zellner J, Hierl K, Mueller M, Pfeifer C, Berner A, Dienstknecht T, Krutsch W, Geis S, Gehmert S, Kujat R, Dendorfer S, Prantl L, Nerlich M, Angele P (2013) Stem cell-based tissue-engineering for treatment of meniscal 
tears in the avascular zone. J Biomed Mater Res B Appl Biomater 101(7): 1133-1142. https://doi.org/10.1002/jbm.b.32922

Zellner J, Pattappa G, Koch M, Lang S et al (2017) Autologous mesenchymal stem cells or meniscal cells: what is the best cell source for regenerative meniscus treatment in an early osteoarthritis situation? Stem Cell Research \& Therapy 10(8 (1)):225. https://doi.org/10.1186/s13287-017-0678-Z

Zhang Z, Arnold JA (1996) Trephination and suturing of avascular meniscal tears: a clinical study of the trephination procedure. Arthroscopy : the journal of arthroscopic \& related surgery : official publication of the Arthroscopy Association of North America and the International Arthroscopy Association $12(6): 726-731$

\section{Submit your manuscript to a SpringerOpen ${ }^{\bullet}$ journal and benefit from:}

- Convenient online submission

Rigorous peer review

- Open access: articles freely available online

- High visibility within the field

- Retaining the copyright to your article

Submit your next manuscript at $\boldsymbol{\sim}$ springeropen.com 